\title{
From Learning Game to Adaptive Ubiquitous Game Based Learning
}

\author{
https://doi.org/10.3991/ijet.v14i16.10701 \\ Lamyae Bennis $\left({ }^{\bowtie}\right)$, Said Amali \\ University Moulay Ismail, Meknes, Morocco \\ lamyaebennis@gmail.com
}

\begin{abstract}
Mobile Learning (also known as m-learning) and game-based learning (GBL) are two important elements in Technology-Enhanced Learning. By using mobile technology and benefiting from their features we can provide a pervasive learning without being restricted by time and space (Learning anywhere and anytime). GBL over the last decade has played an important role in increasing the motivation of the learner player through the integration of gamification into the learner's learning process. The combination of the two elements gave birth to a new concept of educational system called Ubiquitous Learning Game (ULG). Mobile technologies are very diverse and market demands push the continued development of new technologies and features that present a big challenge in time and development costs. On the other hand creating a nice game for different player profiles requires the addition of the learner's model in the design phase of the game. In this sense the main aim of this paper is to present the new architecture of the $<$ e-Adventure $>$ educational adventure games authoring tool and its implementation by addressing the different challenges already cited in order to generate an adaptive ULG for multiples mobile platforms.
\end{abstract}

Keywords - Learning Game, Ubiquitous Learning Game, Authoring Tool, Mobile Learning, Technology-Enhanced Learning.

\section{Introduction}

The nature of human's learning has been typically changed from the traditional to the modern methods thanks to the fast revolution of technologies [1]. The worldwide technological revolution has interpreted as the widespread use of mobile technology the Smartphone is one of the most utilised mobile technologies as its purchase rate is approximated to achieve $88 \%$ of total cellular phone sales by 2018[2]. Seyed Ebrahim et al. (2014) assured that m-learning is a type of learning where new education approaches afforded through mobile devices [3]. The use of cellular phone, such as PDAs, tablets, smart phones, ultra-mobile computers, personal navigation devices, as education tools, promotes innovation and supports learners, and instructors [4]. Mobile devices can also produce more lively learning involvements that develop student commitment, education, and lesson retention [5]. 
By involving the Mobile technologies in education, we can satisfy the advanced Instruction learning requests and achieving an innovative and learner-centered educational manner [6]. As well as enhancing learner motivation, which is an essential part of learning, handing over information when desired, emboldening to solve problems and gratify inquisitiveness [7]. Grosso, 2003; has defined m-learning as an acquiring of several information and skills by utilizing mobile technologies. Keegan (2001) defines m-learning as an execute of learning content via PDAs, pocket PCs and mobile phones [8]. "m-learning is a type of learning model allowing learners to obtain learning materials anywhere and anytime using mobile technologies and the internet" [9]. "UbiqGames are a genre of mobile learning games based on casual design, which enables them to fit more easily into the formal school setting by being played in short, frequent bursts throughout the day" [10]. And as the core idea underlying the adaptive ULG is to transform the educational system using a holistic approach to the Technology-Enhanced Learning (TEL) with an emphasis on students. This kind of education and knowledge are granted to everyone, anytime and anywhere. The vision of developing the smart classrooms is to utilize vital components required for taking advantage of technology in order to improve the educational system and the delivery means. The key target of this paper is to adapt a pre-existing educational adventure games authoring tool "eAdventure" to multiple mobile devices permitting to facilitate the sharing and dissemination of generated ULG into different platforms such us Android, iOS, Mac OS and Windows, reducing costs and development times and the most important thing is that allowing the good integration of the Gamification with Education which is a difficult task [11].

\subsection{Mobile devices and their motivational impact in adapting learning}

Mobile technologies offer an occasion for an essential transformation in teaching away from infrequent usage of computer in a laboratory towards further entrenched us-age in the classroom and outside [12]. They proposal education experiences which can efficiently involve, teach Modern apprentices and which are often evidently dissimilar from those endured by classical Desktop computers [13]. These devices are utilized powerfully, in diverse settings, providing entree to a wide-ranging of usages and located learning events. To increase the student motivation and their attentiveness in a subject we have identify four properties of mobile devices which can be adapted in the Learners motivation context: Individuality, Portability and Mobility, Connectivity, Adaptability [14] [35].

- Individualism: Personalized learning is training that proposes pedagogy, curriculum, and learning surroundings to respond to personal student's requirements. Thanks to the use of mobile device learning process are personalized can vary in time (when to learn), place (where to learn) and context providing more learners independence and individualism.

- Portability and mobility: The little dimension and weight of portable devices provide them with the ability to be taken to diverse places which facilitate the mobility and the capability to relate to activities in the outdoor world moreover deliv- 
ers students with the aptitude to run off the classroom and participate in activities that do not match with both the teacher's schedule and the curriculum. The strong relation between learning. Context and the situation in which the learning needs take place have been broadly discussed in the literature [15] [16] the advantages of just-in-time, located learning have been investigated [17].

- Connectivity: Shared network can be created by connecting mobile devices to another or to a public network allowing learners to share data, files and message. As well as most student by this time have handheld devices, many informative establishments are utilizing wireless technology to download and distribute mobile learning [18] further augmenting possibilities for communication and collaboration between learners enhancing apprentice's motivation levels.

- Adaptability: Adaptability to the learning context includes learners' knowledge, skills, and preferences. To raise the passion to learn it will be useful to regulate the structure of the courses and training to the learners. The courses should be perfectly organized in a manner that gives the generation, development and preservation of education motivation [19].

\subsection{Gamification and game mechanics}

The Gamificaiton is to "inspire the ingredients that made the success of games rewards, challenges, personal growth, and apply them to other areas" as defined by Sandrine Cochard Glance. And as under-lined by Alexandre Roberge in Thot Cursus this Gamification does not affect trading companies only.

Gamification is defined as the idea of using game-design reflection into none-game situation, to make them more amusing, attractive and change user's comportment [20][36], education also tries to incorporate the game in its bank of educational tools: educational gamification suggests the usage of game-like rule systems, entertainer skills and ethnic characters to profile apprentice's Comportment [21]. In the earlier research study Sandberg and al. (2011) discover that a lot of kids applied a trial-anderror tactic on play the games [22]. For this purpose, gamifying a lesson would be a genial aid to primary apprentice' $s$ by taking benefit of the motivational rule of games and apply it to the motivational problems in teaching and as a result we will have an effective learning [23]. On the other hand, many researches in this field affirm that Mobile technologies can be used as an influential reasoning tool inside constructivist method to resolve difficult problems and to involve learners in realistic and significant events [24], gamification is still founded on technology, and it's practically always functional with desktop, web or Smartphone application [25].

Unlike gamification, Mobile game-based learning relates to the use of mobile games to enhance the learning experience. "Mobile game-based learning is a game that contains a summary of the subject of the lesson, is built at different levels of education, is adapted to the current curriculum, and can run on mobile devices"[26]. 


\subsection{The challenge}

A big part of the searches on the use of the mobile techniques for the Game Based Learning is pulled by the technical capacities of new devices. There is nothing surprising about that, considering the face in fast evolution of the mobile computing. These new capacities inspire new practices which can drive to valued effects.

Besides, of numerous researches in this domain bring back that the cost of games development is widely determined by the type of application, such as developing an intricate visually wealthy mobile game like the adventure game is a time-consuming and expensive process. So, a game as real racing 2 apparently costs $\$ 2$ million. consequently, a set of complete solution can cost up to 300.000 \$.

Additionally, recent work in this field reports that the application of the theory in the use of these technologies in educational purposes is confronted to many obstacles. For examples concerning the not multiplatform Learning Games, developed natively for every target Mobile platform, they allow to realize varied and quality Game Based Learning taking advantage of all the power and the ergonomics got by the target platform. But the development cost and times is practically multiplied by the number of target Platforms.

Moreover, the development of personalized applications multiplatform requires a big expertise in the coding and the integration of software. This is a heavy load for the designers of mobile games who need to adapt the games for all these devices and for the novice instructors who have no computing skills.

\subsection{The current eAdventure architecture and its limits}

The eAdventure platform is an open source tool for authoring educational games or learning games, it simplifies the process of creating $2 \mathrm{D}$ point and click conversational adventure game by novice's users in order to facilitate their adoption and bring them closer to the educational community. eAdventure started in 2007, being the main result of Pablo Moreno's doctoral thesis as a research project of "e-UCM" laboratory. It's coded in java and supported by many operational systems like MAC OS, Windows and Linux. eAdventure has received contributions from many people, until it becomes a stable product with more than 10,000 downloads per year (data from SourceForge.net) and available in 10 languages.

The current eAdevnture architecture includes two focal applications the eAdventure Editor and the eAdventure Engine Core. The eAdventure Editor (Game description) allows to novice designer to choose the different game component such us characters, items, assets or game scenarios. Following the game description the user generates his LG, at this phase the eAdventure Engine reads the EAdElements from an XML File, generated by the eAdventure editor, and converts them to Game Objects in order to have a functional LG. Based on the factors already cited in the section 1.3, we can detect that the current eAdventure architecture functional is very limited. For this reason, we propose an extended version of the current eAdventure architecture called the me Adventure in order to add flexibility and adaptability to the generated ULG. 


\section{Our Approach: Extending eAdventure Architecture to me Adventure}

\subsection{Me adventure extending editor: mobile device characteristics layer}

The adaptation of learning game content according to the mobile device characteristics. must be one of the most important steps in the generation of adaptable Mobile Learning Game. Characteristics of mobile devices are increasingly evolved and development costs are quite expensive. Personal digital assistants (PDAs), smart phones or cell phones these devices differ widely from each other by their hardware and software capabilities, processor power, memory size, screen resolution, operating system, web browser, supported scripting languages, supported file formats [27]. The focal characteristics on which we are based in this research work are:

- Mobile device type (DeviceName): The first step of adaptation is to identify the type of the target mobile device (Notebooks, PDAs, Smartphone, cell phones).

- Memory size (MemoSize): The interior memory size diverges from device to device. The designer must define how much memory we really require to run the generated Learning Game on our Smartphone.

- Screen resolution (ScreenRes): This is an essential feature during the process of adaptation because at the moment there are a wide variety of screen resolutions from smalls ones of the cell phones to the big ones of notebooks.

- Screen mode (ScreenMod): It's very important to determine the screen mode for example portrait or landscape, new PDAs can switch between the two screen modes.

- Operating System (OS): Introduced by the International Data Corporation (IDC) Android is the most famous Smartphone operating system in the world from 2016.

Since its launch, sales of Smartphone running Android have increased sharply over the years. Apple's iOS is the second most popular operating system for Smartphone.

In 2017Q4, Apple's iOS market share has varied between 19.6 and 13.2 percent

(See Table 1). Due to this discussion the target mobile operating system (OS) is Android and iOS (See Fig1). 


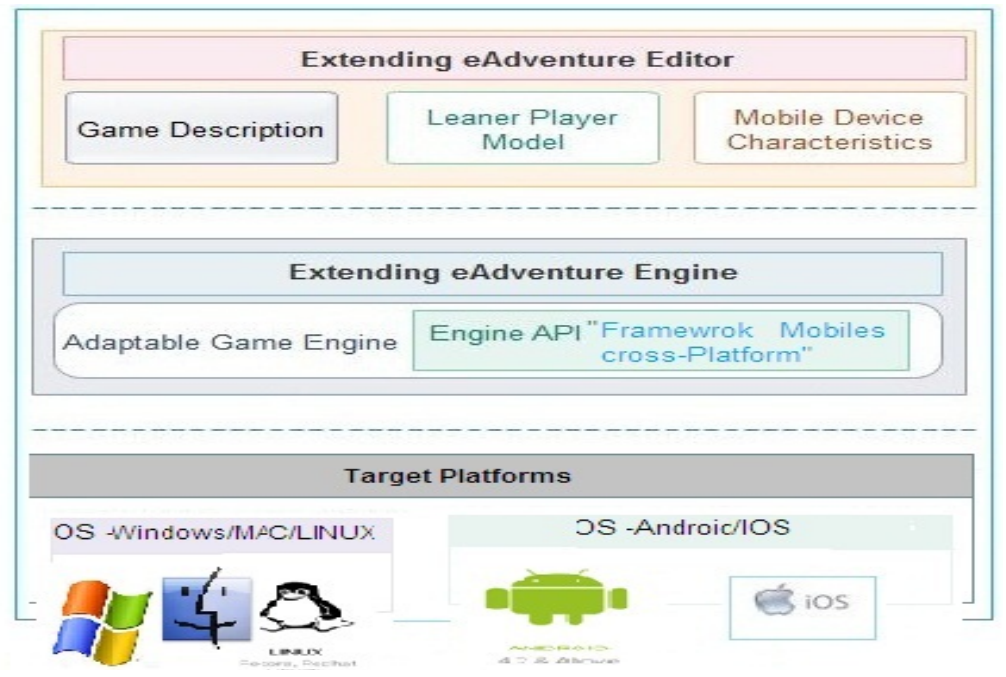

Fig. 1. The Extending Architecture of the eAdventure

Table 1. Smartphone Mobile OS Market Share,2018 (IDC)

\begin{tabular}{|l|c|c|c|c|}
\hline \multirow{2}{*}{ Operating System (OS) } & \multicolumn{4}{c|}{ Quarter } \\
\cline { 2 - 5 } & $\mathbf{2 0 1 7 Q 4}$ & $\mathbf{2 0 1 8 Q 1} \mathbf{2 0 1 8 Q 2}$ & $\mathbf{2 0 1 8 Q 3}$ \\
\hline Android & $80.3 \%$ & $84.3 \%$ & $87.8 \%$ & $86.8 \%$ \\
\hline iOS & $19.6 \%$ & $15.7 \%$ & $12.1 \%$ & $13.2 \%$ \\
\hline Others & $0.1 \%$ & $0.0 \%$ & $0.1 \%$ & $0.0 \%$ \\
\hline Total & $100 \%$ & $100 \%$ & $100 \%$ & $100 \%$ \\
\hline
\end{tabular}

\section{2 meAdventure extending editor: learner player model layer}

A lot of research shows that personalised teaching is better-quality to the traditional instruction approaches of one-size-fits-all [28]. Individualizing learning content are estimated as the notion base in the field of education design and specifically in learning game design while designing an adaptive learning game necessitates taking into account individual differences between learners such as apprentices' diversities in basic knowledge, skills and abilities; interests; differences in demographic and biographic; and differences in emotional variables (such as motivation) [11] [29][18].

For this reason, the learner player model component have been integrated as an essential part in the proposed eAdventure architecture as shown in Fig 1. This model contains information for understanding and detecting what are the learner's player needs and preferences as shown in Fig 2. 


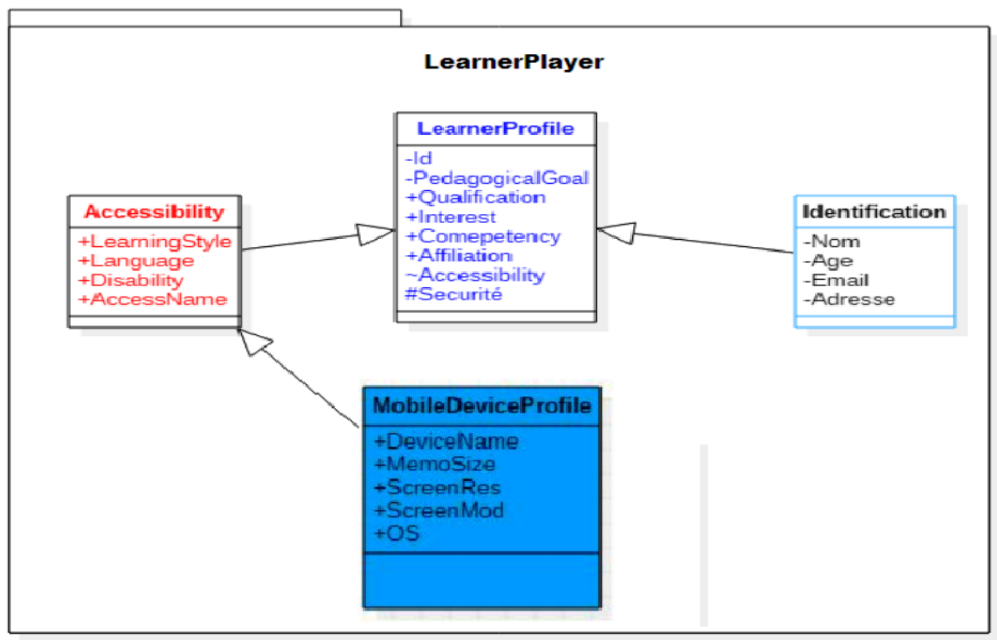

Fig. 2. The Learner Player Package

The information in this model is managing based on the IMS-Lip learning standards (See Table 2). IMS LIP (learners information package specification) model focal point on the performance and activities of the learner, and gives an ordered profile model, is one of the most used standards in the current learning systems [30].

- The identification: Contains the demographic and biographic information

- Age: Describes age of learner's player "An UGL designed for kids cannot be reused by adults or teenagers"; Name; Email; Sexe: Defines Learners sexe for example females like pink color whereas male prefers blue color.

- The goal: Describes the educational objectives of Learning Game.

- Qualifications (QCL): Describes all diplomas and certification obtained by the learner.

- Transcription: University name or school description.

- Affiliation: Brings information of partisanship in qualified Organizations.

- Accessibility: Illustrates the Learner's Player disabilities and preferences such as (Language; Learning Styles; Disability).

- Language attribute: Refers to learner's player's spoken language as it's one of the potential factors that can prevent the learning process [31] and many researchers shows that Learners are more motivated to learn when the story in the LG environment is in their native language [32]; Learning Style Attribute: Learning Style in this research refers to the favourite manner of learning. Designer can choose the best learning path according to the learner learning style, using the index learning styles of Felder-Solomon (ILS)(Felder and Silverman 1988)[33], assessment tool to identify it, in order to generate an adaptable UGL and to augment the learners player motivation [34] [18] and we have an attribute to define the mobile device platform profile (Mobile device characteristic's). Disability: Mobile technology has 
an incredible impact and maintains successfully the learning of children with special needs [35].

Table 2. Learner Player Model Elements

\begin{tabular}{|l|l|}
\hline \multicolumn{1}{|c|}{ Learner Player Model Elements } & \multicolumn{2}{c|}{ IMS-LIP Attribut } \\
\hline Age; Name; Email; Sexe & Identification \\
\hline Educational Objectives of Learning Game & The Goal \\
\hline Last Diploma Obtained & Qalification (QCL) \\
\hline University Name or School Description & Transcription \\
\hline Affiliation & Affiliation \\
\hline Learning Style; Disability; Mobile Device Profile; Language & Accessibility \\
\hline
\end{tabular}

\section{3 meAdventure Extending Engine: Engine API (Frameworks mobiles cross- platforms)}

Comparing many Cross-platform frameworks such us: PHONEGAP, TITANIUM, RHOMOBILE, FLEX, QUICK CONNECT and CORONA SDK. By analyzing advantages and disadvantages of each mobile programming method based on the following criteria: Mobile API, an access to mobile phone features like geolocation; Operating system Support (IOS, Android); The framework documentation availability; Fast development; The accessibility (license Open source or low license costs). The chosen one is CORONA SDK.

Corona SDK is a mobile development framework for creating applications and games for the iPhone, iPad, and Android. The idea of integrating Corona SDK crossplatform mobile framework is that with the same codebase (XML) edited by meAdventure editor (See Fig1). The meAdventure engine could generate Mobile Game Based Learning for multiple mobile phone platforms meeting the device criteria already sized by designer. That would decrease the development costs and time

\section{Conclusion}

In this paper, we introduced the proposed new architecture of the eAdventure called meAdventure based on the integration of learner's player model and mobile device features in the Meta layer of the extending eAdventure Editor. We also introduced the extending Meta layer of the eAdventure engine by the integration of Corona SDK smartphone cross platform stackes the challenge to create an adaptive ubiquitous learning game (ULG). On the other hand, our future Works involves the generation and evaluation of ULG using the meAdventure architecture.

\section{$4 \quad$ References}

[1] Mohd Shafie Rosli, Nor Shela Saleh, Baharuddin Aris, Maizah HuraAhmad, and Shaharuddin Md Salleh. Ubiquitous hub for digital natives. International Journal of Emerging Technologies in Learning (iJET), 11(02):29-34, 2016. https://doi.org/10.3991/ijet.v11i02.4993 
[2] R Van der Meulen and J Rivera. Gartner says worldwide traditional pc, tablet, ultramobile and mobile phone shipments on pace to grow7.6 percent in 2014. Retrieved September, 29:2015, 2014.

[3] H Seyed Ebrahim, K Ezzadeen, and AK Alhazmi. Acquiring knowledge through mobile applications. International Journal of Interactive Mobile Technologies, 9(3), 2015.

[4] Ahmed Al-Hunaiyyan, Salah Al-Sharhan, and Rana Alhajri. A new mobile learning model in the context of smart classroom environment: A holistic approach. International Journal of Interactive Mobile Technologies, 11(3), 2017. https://doi.org/10.3991/ijim.v11i3.6186

[5] T Joosten. Mobile learning and social media: Increasing engagement and interactivity. In New Media Consortium Conference, pages 9-12, 2010.

[6] Kil Hong Joo and Sang Hong Kim. Development and application of an efficient ubiquitous teaching and learning model. In Advanced Communication Technology, 2009. ICACT 2009. 11th International Conference on, volume 3, pages 2165-2168. IEEE, 2009.

[7] Mike Sharples, Dan Corlett, and Oliver Westmancott. The design and implementation of a mobile learning resource. Personal and Ubiquitous Computing, 6(3):220-234, 2002. https://doi.org/10.1007/s007790200021

[8] D Keegan. The future of learning: Ziff papiere 119: From eLearning to mlearning. Online document, 2002.

[9] Yu-Feng Lan and Yang-Siang Sie. Using rss to support mobile learning based on media richness theory. Computers \& Education, 55(2):723-732, 2010.https://doi.org/10. 1016/j.compedu.2010.03.005

[10] Eric Klopfer, Josh Sheldon, Judy Perry, and VH-H Chen. Ubiquitous games for learning (ubiqgames): Weatherlings, a worked example. Journal of Computer Assisted Learning, 28(5):465-476, 2012. https://doi.org/10.1111/j.1365-2729.2011.00456.x

[11] Lamyae Bennis and Said Benhlima. Comparative study of the process model of serious game design through the generic model dice. In Intelligent Systems and Computer Vision (ISCV), 2015, pages 1-5. IEEE, 2015. https://doi.org/10.1109/isacv.2015.7105539

[12] Sara Hennessy. The potential of portable technologies for supporting graphing investigations. British Journal of Educational Technology, 30(1):57-60, 1999. https://doi.org/10. $1111 / 1467-8535.00090$

[13] Zh K Zhalgasbekova, GA Shakhanova, AE Karymsakova, Sh S Tutkyshbayeva, ZA Kutpanova, RE Abdualiyeva, and N Shyndaliyev. Creating and using mobile physics and mathematics applications in the learning process as one of teaching methods to increase the quality of student's knowledge. EURASIA Journal of Mathematics, Science and Technology Education, 14:12, 2018. https://doi.org/10.29333/ejmste/97837

[14] Eric Klopfer, Kurt Squire, and Henry Jenkins. Environmental detectives: Pdas as a window into a virtual simulated world. In Wireless and Mobile Technologies in Education, 2002. Proceedings. IEEE International Workshop on, pages 95-98. IEEE, 2002. https://doi.org/10.1109/wmte.2002.1039227

[15] John Seely Brown, Allan Collins, and Paul Duguid. Situated cognition and the culture of learning. Educational researcher, 18(1):32-42, 1989. https://doi.org/10.3102/0013189 $\mathrm{x} 018001032$

[16] Jean Lave and EtienneWenger. Situated learning: Legitimate peripheral participation. Cambridge university press, 1991.

[17] Peter Goodyear. Environments for lifelong learning. In Integrated and holistic perspectives on learning, instruction and technology, pages 1-18. Springer, 2000. https://doi.org/10. 1007/0-306-47584-7

[18] Lamyae BENNIS, Said BENHLIMA, and M Ali BEKRI. An authoring tool for generating an adaptive mobile game-based learning.

[19] Paula Figas, Georg Hagel, and Alexandre Bartel. The furtherance of motivation in the context of teaching software engineering. In Global Engineering Education Conference (EDUCON), 2013 IEEE, pages 1299-1304, 2013.https://doi.org/10.1109/educon. 2013.6530274

[20] Alexander Bartel and Georg Hagel. Engaging students with a mobile game-based learning system in university education. In EDUCON, pages 957-960, 2014. https://doi.org/10. $\underline{1109 / \text { educon.2014.6826215 }}$ 
[21] Chung-Ho Su and Ching-Hsue Cheng. A mobile game-based insect learning system for improving the learning achievements. Procedia-Social and Behavioral Sciences, 103:42-50, 2013. https://doi.org/10.1016/j.sbspro.2013.10.305

[22] Jacobijn Sandberg, Marinus Maris, and Kaspar de Geus. Mobile English learning: An evidence-based study with fifth graders. Computers \& Education, 57(1):1334-1347, 2011. https://doi.org/10.1016/j.compedu.2011.08.009

[23] Marc Prensky. Fun, play and games: What makes games engaging, 2001.

[24] DHJonassen and TC Reeves. Learning with technology: Using computers as cognitive tools. ind. h. jonassen (ed.), handbook of research for educational communications and technology (pp. 693 719), 1996.

[25] Adrián Domínguez, Joseba Saenz-de Navarrete, Luis De-Marcos, LuisFernández- Sanz, Carmen Pagés, and José-Javier Martínez-Herráiz. Gamifying learning experiences: Practical implications and outcomes. Computers \& Education, 63:380-392, 2013. https://doi.org/10. 1016/j.compedu.2012.12.020

[26] Ucu Cahyana, Maria Paristiowati, Dwi Amelia Savitri, and Siti Nuryana Hasyrin. Developing and application of mobile game-based learning (m-gbl) for high school students performance in chemistry. Eurasia J. Math. Sci. Technol. Educ, 13(10):7037- 7047, 2017. https://doi.org/10.12973/ejmste/78728

[27] Evgeniya Georgieva and Tsvetozar Georgiev. Methodology for mobile devices characteristics recognition. In Proceedings of the 2007 international conference on Computer systems and technologies, page 71. ACM, 2007. https://doi.org/10.1145/1330598.1330674

[28] Mieke Vandewaetere, Piet Desmet, and Geraldine Clarebout. The contribution of learner characteristics in the development of computer-based adaptive learning environments. Computers in Human Behavior, 27(1):118-130, 2011. https://doi.org/10.1016/j.chb.2010.07.038

[29] Lamyae Bennis, Said Benhlima, and M Ali Bekri. Learner's player model for designing an effective game-based learning. In Progress in Advanced Computing and Intelligent Engineering, pages 157-165. Springer, 2019. https://doi.org/10.1007/978-981-13-1708-8 15

[30] Inssaf El Guabassi, Mohammed Al Achhab, Ismail Jellouli, and Badr Eddine El Mohajir. Towards adaptive ubiquitous learning systems. International Journal of Knowledge and Learning, 11(1):3-23, 2016. https://doi.org/10.3991/ijet.v13i12.7918

[31] Nattavud Pimpa. Engaging international business students in the online environment. The international journal of management education, 9(3):77-89, 2011 https://doi.org/10. 3794/ijme.93.323

[32] Mazeyanti Mohd Ariffin, Alan Oxley, and Suziah Sulaiman. Evaluating game-based learning effectiveness in higher education. Procedia-Social and Behavioral Sciences, 123:20-27, 2014. https://doi.org/10.1016/j.sbspro.2014.01.1393

[33] Richard M Felder, Linda K Silverman, et al. Learning and teaching styles in engineering education. Engineering education, 78(7):674-681, 1988.

[34] Kuo-Kuang Fan, Peng-wei Xiao, and Chung-Ho Su. The effects of learning styles and meaningful learning on the learning achievement of gamification health education curriculum. Eurasia Journal of Mathematics, Science \& Technology Education, 11(5), 2015.https://doi.org/10.12973/eurasia.2015.1413a

[35] Kraleva, R., \& Kralev, V. (2018). An Evaluation of The Mobile Apps for Children with Special Education Needs Based on The Utility Function Metrics. International Journal on Advanced Science, Engineering and Information Technology, 8(6), 2269-2277. https://doi.org/10.18517/ijaseit.8.6.6309

[36] Khaleel, F. L., Sahari, N., Wook, T. S. M. T., \& Ismail, A. (2016). Gamification elements for learning applications. International Journal on Advanced Science, Engineering and Information Technology, 6(6), 868-874. https://doi.org/10.18517/ijaseit.6.6.1379

\section{$5 \quad$ Authors}

Lamyae Bennis is a $\mathrm{PhD}$ student of Computer Sciences at Moulay Ismail University, Meknes Morocco. She is a member of the Mathematics and Computer Sciences $\mathrm{Lab}$ in the Faculty of Sciences of Meknes. Lamyae does research in serious games, 
Information Science, Teacher Education and Teaching Methods. Their current project is the conception and development of an authoring tool in order to generate an adaptive Ubiquitous learning Games. Email id: lamyaebennis@gmail.com

Said Amali is a Professor of Computer Sciences at Moulay Ismail University, Meknes Morocco. He is a member of the Mathematics and Computer Sciences Lab in the Faculty of Sciences of Meknes. His research is focused on the area of optimizing the learning path in a distance learning system (e-learning) and learning technologies. $\mathrm{He}$ is a director of many doctoral theses.

Article submitted 2019-04-19. Resubmitted 2019-07-12. Final acceptance 2019-07-12. Final version published as submitted by the authors. 